\title{
ATIVISMO JUDICIAL E ESTADO DE DIREITO
}

\author{
Carlos Eduardo Dieder Reverbel ${ }^{1}$
}

Introdução. 1. Essência do humano: a natural sociabilidade. 2. Os princípios do Estado de Direito. 3. Estado de Direito e os sistemas jurídicos. 4. O sistema romano-germânico e o princípio da legalidade jurídica devida. 5. O sistema da common law e o princípio do processo jurídico devido. 6. A contribuição de McILWAIN ao Estado de Direito: jurisdictio y gubernaculum. 7. Estado de direito e de democracia: os problemas do ativismo judicial. Conclusão. Bibliografia.

\section{Introdução}

O presente trabalho insere-se na Teoria do Estado e no Direito Constitucional. Parte da natural sociabilidade do humano para demonstrar que o Estado de Direito nasce para servir a pessoa, e esta abdica parte de sua liberdade em prol de um convívio harmônico e pacífico dentro da sociedade. Delimita, mesmo que não desenvolva, o que entende ser os princípios de Estado de Direito. Após, insere o estudo dentro das duas principais famílias de direito: common law e romano-germânica; apresentando o princípío prevalente em cada uma delas: legalidade e processualidade. Desenvolve distinção de McILWIAN entre jurisdictio y gubernaculum, pois o Estado de Direito só pode ser aquele que delimite e proteja uma área restrita à Política, e uma área restrita ao Direito. Por fím, antes da conclusão e da bibliografia, mostramos os entraves que o ativismo judicial - inclusive colacionando jurisprudências - tem gerado para o florescimento de um Estado de Direito racional.

\section{Essência do humano: a natural sociabilidade}

$\mathrm{Na}$ definição de Boécio $^{2}$, aprimorada por Tomás de Aquino $^{3}$, Persona est rationalis naturae individua substantia. Três seriam, portanto, as características da pessoa: substancialidade, racionalidade e individualidade.

Em sua (1) substância o ser humano é composto de corpo e alma, matéria e espírito; pela (2) racionalidade, extraímos que "significa lo que hay más perfecto en toda naturaleza, es decir, lo subsistente en una naturaleza racional ",; pela sua (3) individualidade, alteridade, do latim altero (no outro, com o outro), o ser humano apresenta esta perplexidade: um ser totalmente individual e totalmente social.

\footnotetext{
${ }^{1}$ Doutorando em Direito do Estado pela Universidade Federal do Rio Grande do Sul. Professor Universitário da UniRitter, da São Judas Tadeu e professor substituto na UFRGS. Este artigo recebeu prêmio de menção honrosa ao ser apresentado na USP no XVIII Encontro Nacional de Direito Constitucional - Instituto Pimenta Bueno - Associação Brasileira dos Constitucionalistas.

${ }^{2}$ BOÉCIO. De duabus nat., II, 4. Tomás de Aquino define a pessoa pelos caminhos abertos por Boécio: "Persona es el nombre distintivo de la sustancia individual de uma naturaleza racional entre todas las demas sustancias.” (AQUINO, Tomás de. Suma Teológica. Madrid: Moya y Plaza, 1880, I-I, 29, a.1).

${ }^{3}$ AQUINO, Tomás de. Suma Teológica. Madrid: Moya y Plaza, 1880, I-I, 29, a.3.

${ }^{4}$ AQUINO, op. cit., I-I, 29, a.3.
} 
Mas é dessa natural sociabilidade do humano que devemos extrair os princípios que darão fundamento e regramento às atividades jurídicas que dizem respeito à Pessoa Humana e a sociedade como um todo. Neste sentido, o Estado é meio - e não fim - à realização da Pessoa. A Pessoa Humana é, portanto, anterior e ulterior ao Estado. ${ }^{5}$

O Estado de Direito, assim, serve à pessoa e à sociedade. Todos - e cada um - abdicam parte de sua individualidade em prol de uma mediação técnico-jurídica, instrumentada e concretada em realidades distintas, que modernamente vem ganhando o nomem iuris de Estado de Direito.

O Estado de Direito ${ }^{6}$ ganhou, podemos dizer, formas distintas nas famílias de direito ${ }^{7}$. Assim, as famílias - sistemas - de Direito concretizam princípios ínsitos às suas realidades históricas. Em sua essência - defesa dos valores - veremos uma linha comum de proteção e implementação da Supremacia do Direito, é, entretanto, no seu exercício, na sua concreção, na própria aplicação contenciosa pelo poder judiciário, e não contenciosa pelo poder executivo que as diferenças do ativismo aparecem nos sistemas de direito, seja na Rule of Law, no État de Droit ou mesmo no Rechtsstaat ${ }^{8}$.

\section{Os princípios do Estado de Direito}

Jorge Miranda classificou os princípios constitucionais da seguinte forma: (1) princípios constitucionais substantivos, que abarcariam tanto princípios axiológicos fundamentais, quanto princípios político-constitucionais; e (2) princípios constitucionais adjetivos ou instrumentais ${ }^{9}$.

Inspirados na doutrina de JORGE MIRANDA aplicamos ao Estado Democrático de Direito uma classificação principiológica dividida em três níveis (axiológico, político e técnico-instrumental), cada um dos níveis foi dividido em cinco princípios ${ }^{10}$ :

\footnotetext{
${ }^{5}$ SOUZA JUNIOR, Cezar Saldanha. (Informação oral). Aulas de Política e Teoria do Estado do Curso de Direito da Universidade Federal do Rio Grande do Sul, $1 .^{\circ}$ semestre de 2006. Sobre a natural sociabilidade do ser humano a bibliografia é vastíssima, por todos, ver GONELLA, Guido. Bases de uma ordem social. São Paulo: Vozes, 1947; BELLO, Pedro Paul. Lo humano: introduccion al personalismo cristiano. Caracas: IFEDEC, 1987.

6 A expressão Estado de Direito, segundo Luc HEUSCHLING foi "créé em 1798 par Johann Wilhelm Placidus (1758-1815)" (État de Droit, Rechtsstaat, Rule of Law. Paris: Dalloz, 2002). FERREIRA FILHO, citando Hayek, refere que "ela aparece num livro de Welcker, publicado em 1813, no qual se distinguem tres tipos de governo: despotismo, teocracia e Rechtsstaat”. (In: Estado de Direito e Constituição. São Paulo: Saraiva, 2007, p. 5).

${ }^{7}$ Sobre a Supremacia do Direito e os sistemas de famílias jurídicas, ver: SOUZA JUNIOR, Cezar Saldanha. A Supremacia do Direito no Estado Democrático e seus Modelos Básicos. Porto Alegre: [s.ed.], 2002, passim.

${ }^{8}$ O tema da Supremacia do Direito já havia sido tratado em um paper de Rainer GROTE, intitulado Rule of Law, État de Droit and Rechtsstaat. Anais do Congresso da Associação Internacional de Direito Constitucional, Roterdam, 12-16 de Julho de 1999; mas foi em 2000 que Estado de Direito é coroado com a tese de doutorado apresentada por Luc HEUSCHLING, publicada em 2002 sob o título, État de Droit, Rechtsstaat, Rule of Law. Paris: Dalloz, 2002. O tema não fugiu à inteligência dos brasileiros, que com maior destaque lembramos FERREIRA FILHO, Manoel Gonçalves. Estado de Direito e Constituição. São Paulo: Saraiva, 2007.

${ }^{9}$ MIRANDA, Jorge. Manual de Direito Constitucional. 3.ed. Coimbra: Coimbra Editora, 1991, Tomo II, p. 229-230.

${ }^{10}$ Esta idéia não é originalidade minha, é fruto de um diálogo que venho desenvolvendo com meu orientador desde os tempos da graduação. Sobre os princípios do Estado de Direito, por todos, ver: FERREIRA FILHO,
} 
(1) Princípios axiológicos do Estado de Direito

(a) Dignidade da Pessoa Humana (Art. $1^{\circ}$, III, CRFB/88);

(b) Subsidiariedade (Art. $1^{\circ}$, IV e Art. 173, CRFB/88);

(c) Pluralismo das dimensões humanas;

(d) Bem Comum (Art. $3^{\circ}$, IV, CRFB/88); e

(e) Direitos Fundamentais (Art. 5 ${ }^{\circ}, \mathrm{CRFB} / 88$ ).

(2) Princípios políticos do Estado de Direito

(a) Soberania Popular (Art. $1^{\circ}$, I e $\S$ único, CRFB/88);

(b) Cidadania Universal e Plural (Art. $1^{\circ}$, II e Art. 14, CRFB/88);

(c) Pluralismo Político (Art. $1^{\circ}, \mathrm{V}$ e Art. 17, CRFB/88);

(d) Separação de Poderes; e

(e) Separação de Funções.

(3) Princípios técnicos ou instrumentais do Estado de Direito

(a) Princípio da Legalidade;

(b) Princípio da Igualdade;

(c) Princípio da Prospectividade ou Segurança Jurídica;

(d) Princípio da Controlabilidade, Processualidade ou Justicialidade;

(e) Princípio da Razoabilidade ou Proporcionalidade.

O Estado de Direito, na busca do interesse público, implementa, através da razão prática (espaço do agir humano na sua coletividade), o contemplado na razão teórica (esfera filosófica e científica), operando por uma razão técnica (aspecto instrumental de concreção), para efetivar o indispensável à promoção do bem comum.

No campo dos princípios axiológicos do Estado de Direito estamos tratando dos valores supremos da ordem político-constitucional: esfera que trata do consenso da sociedade política, não, havendo, portanto, diferença substancial entre os sistemas de direito nesta esfera.

Entretanto, a mesma correspondência no plano do princípio político e técnicoinstrumental se faz diferente, uma vez que as famílias de Direito, por exigências legislativas, jurídicas e doutrinárias de sua história, não comportariam um tratamento equânime, para questões que foram trabalhadas de forma distintas.

No fundo, esta é a tese de CAENEGEN e SOUZA JUNIOR: tentar mostrar que é imprescindível ao Estado de Direito uma análise da história política, das raízes sociais, bem como das instituições que fazem e operam o Direito ${ }^{11}$.

Manoel Gonçalves. Estado de Direito e Constituição. São Paulo: Saraiva, 2007, seção $4^{\mathrm{a}}$, passim, onde sustenta que a atuação do Poder baseia-se na lei, desdobrando assim os princípios do Estado de Direito em: princípio da legalidade, de onde decorre também o princípio da igualdade, e ambos sob a tutela da justicialidade.

${ }^{11}$ Cf. CAENEGEN, R. C. Van. Judges, Legislators and Professors. Cambridge: University Press, 1996, p. 84, 88-89; SOUZA JUNIOR, Cezar Saldanha. A Supremacia do Direito no Estado Democrático e seus Modelos Básicos. Porto Alegre: [s.ed.], 2002, p. 100, teríamos, nesse sentido, o (1) direito-feito-pelo-juiz (Rule of 
Assim, será importante entender a racionalidade do direito, ao menos, na família da Common Law e da família Romano-Germânica, para mostrarmos como é diferente o "ativismo judicial" desenvolvido, por exemplo, nos Estados Unidos, do ativismo judicial desenvolvido no Brasil. Em verdade, o foco do artigo ficará restrito a estes dois países: Estados Unidos e Brasil, representando o Common Law e o Romano-Germânico, respectivamente.

\section{Estado de Direito e os sistemas jurídicos}

As famílias de Direito apresentam diferenças tão fortes em sua estrutura operacional ${ }^{12} \mathrm{e}$ os juristas que as operam pensam os problemas de forma sistemática, dificultando, de certa forma, a compreensão de realidades alienígenas. Vivendo em uma família de Direito romano-germânica, em que a função precípua do Direito é regular e orientar os aspectos da vida social $^{13}$, somos levados a pensar que essa realidade é idêntica em outros países ${ }^{14}$.

A recíproca é verdadeira: a função precípua de operacionalidade do Direito em família de common law é dar solução a um processo ${ }^{15}$, trabalhando pelo precedente onde atua, não de forma abstrata, mas a partir de um caso concreto ${ }^{16}$.

Assim, a lei, o costume, a jurisprudência, a doutrina, a eqüidade, e os princípios gerais de Direito exercem funções distintas em realidades estatais específicas. A "lei”, neste sentido, em País de common law não exerce a mesma função em País romano-germânico. Da mesma forma, o costume em País romano-germânico não tem a mesma função que exerce em País de common law.

A lei, em sistema da common law - é importante desmistificar desde agora - não passa de um ato do parlamento tendente a tornar-se Direito, quando sofrer a chancela do Poder Judiciário. Não esqueçamos que no common law existe o princípio do rule of exclusion, pelo qual os juízes não estão vinculados aos "princípios da lei", mas simplesmente à literalidade do ato do parlamento ${ }^{17}$.

JEREMY WALDRON afirma, com outras palavras, o aqui expressado:

Law); o (2) direito-feito-pelo-professor (Rechtsstaat) e o (3) direito-dado-pelo-legislador (État Legal que hoje evoluiu para o État de Droit).

${ }^{12}$ Cf. RADBRUCH, Gustav. El espíritu del derecho inglés. Madrid: Marcial Pons, 2001, p. 24, "Ambas culturas jurídicas del mundo civilizado son tan diferentes la una de la otra, que casi es imposible una traducción adecuada de un concepto jurídico en uno de los âmbitos jurídicos al idioma del otro ”.

${ }^{13}$ Ver, SOUZA JUNIOR, Cezar Saldanha. A Supremacia do Direito no Estado Democrático e seus Modelos Básicos. Porto Alegre: [s.ed.], 2002, p. 81.

${ }^{14}$ Esse é o papel dos comparatistas: transcender aos particularismos locais e mostrar outras fontes formais que trabalham a realidade social. Neste ponto, ver os ensinamentos de DAVID, René. Os grandes sistemas de Direito contemporâneo. $4^{\mathrm{a}}$ ed. São Paulo: Martins Fontes, 2002, pp. 13-15 e 18.

${ }^{15}$ Ver SOUZA JUNIOR, Cezar Saldanha. A Supremacia do Direito no Estado e seus Modelos Básicos..., 2002 , p. 81.

${ }^{16}$ Não é outra a lição de RADBRUCH, Gustav. El espíritu del derecho inglés..., p. 24: "En los primeros (romano-germânico) el legislador es el autor del Derecho; en los segundos (common law) lo será juez. En unos, el juicio jurídico emana de la letra de la ley y va al caso concreto, en los otros al revés, del caso concreto a la letra de la ley. En unos, el origen de la Justicia son la ley y el espíritu de la ley; en otros, la vida jurídica y la naturaleza de la cosa".

${ }^{17}$ SOUZA JUNIOR, Cezar Saldanha. A Supremacia do Direito no Estado e seus Modelos Básicos..., p. 104. 
Um projeto de lei não se torna lei simplesmente sendo decretado, ocupando o seu lugar em Halsbury ou no livro de estatutos. Torna-se lei apenas quando começa a desempenhar um papel na vida da comunidade, e não podemos dizer qual papel será - e, portanto, não podemos dizer qual lei foi criada -, até que ela comece a ser administrada e interpretada pelos tribunais. Considerado como um pedaço de papel com o selo de aprovação do parlamento, um estatuto não é direito, mas apenas uma possível fonte de direito ${ }^{18}$.

RENÉ DAVID corrobora o aqui afirmado, ao afirmar que as "leis" no common law são encaradas como um fenômeno de exceção. Reconhece, ainda, a vinculação à literalidade na forma de interpretação, mas afirma, categoricamente:

De qualquer modo, os juristas ingleses continuam a sentir-se pouco à vontade em presença das regras formuladas pelo legislador; eles as envolverão tão rapidamente quanto possível, sob a onda de decisões jurisprudenciais com vista à sua aplicação ${ }^{19}$.

\section{O sistema romano-germânico e o princípio da legalidade jurídica devida}

É nos princípios técnicos ou instrumentais e políticos do Estado Democrático de Direito que encontramos a maior diferenciação entre as famílias de Direito. No plano axiológico, em nível de valores supremos, há consenso acerca das necessidades de preservá-los; entretanto, é na realidade político-técnico-instrumental que as diferenças aparecem, sendo executadas, juridicializadas, aplicadas de formas diferentes.

No Ocidente europeu, a partir do século XII, a sociedade conscienciosa da impossibilidade de se continuar resolvendo as relações civis ao apelo sobrenatural ${ }^{20}$, retoma, com base nas compilações de Justiniano, o modelo utilizado pelo Direito Romano nas relações entre particulares. A sociedade quer um Direito fundado na justiça, de acordo com a moral, para ajudar no funcionamento da sociedade.

O Direito Romano ensinado nas Universidades vai evoluir. Os pós-glosadores estudam a fundo este Direito, procurando reencontrar e explicar o sentido originário das leis romanas. O Direito Romano passa a ser adaptado às novas necessidades, formando-se, lentamente, um jus commune do sistema romano-germânico, que respeitava às diversidades locais, por sua flexibilidade na busca de soluções justas.

A Escola de Direito Natural, já nos séculos XVII e XVIII, afastar-se-á, em diferentes pontos, dos pós-glosadores, pretendendo construir a ordem social sobre o sujeito, exaltando os "direitos naturais do indivíduo", e reconhecendo à razão humana o único guia. Ela

\footnotetext{
${ }^{18}$ WALDRON, Jeremy. The Dignity of Legislation. Cambridge: Cambridge University Press, 1999, p. 11. “A bill does not become law simply by being enacted, or taking its place in Halsbury or in the statute book. It becomes law only when it starts to play a role in the life of the community, and we cannot tell what law it is that hás been created - until the thing begins to be administered and interpreted by tho courts. Considered as a piece of paper with the stamp of parliamentary approval, a statute is not law, but only a possible source of law”.

${ }^{19}$ DAVID, René. Os grandes sistemas de Direito contemporâneo..., p. 16.

${ }^{20}$ Cf. DAVID, René. Os grandes sistemas de Direito contemporâneo..., p. 42, o Direito local costumeiro, aos olhos da Universidade não era propriamente direito. "Non est proprie jus, sed fex".
} 
propugna, em verdade, um Direito público que reconheça os direitos naturais do homem. A porta à codificação está aberta; e a lei ganharia relevo no século XIX. ${ }^{21}$

$\mathrm{Na}$ família romano-germânica a lei foi erigida em princípio fundamental para se chegar às soluções justas, devendo os juristas, nas soluções dos casos concretos, estar adstritos às orientações e às regulamentações por ela proposta. Entretanto, ao princípio da legalidade agregar-se-ia "alguns adjetivos importantes, como, por exemplo, igual, prospectiva, controlável (razoável, proporcional). Pode soar estranha, mas não deixa de ser o princípio da legalidade juridicamente devida, ou seja, da legalidade com certas qualificações jurídicas mínimas ${ }^{22,}$.

Assim - em um sistema que tem por base a lei - a percepção do ativismo judicial parece ser um mal maior. Mas certamente este ativismo judicial, ao menos no Brasil, possui raízes mais profundas, como o desprestígio da lei, a ineficiência do executivo, a desestruturação do sistema, a irracionalidade das instituições, a ausência de uma boa política, a falta de consenso sobre pontos fundamentais.

\section{O sistema da common $\operatorname{law}^{23}$ e o princípio do processo jurídico devido}

O estudo da família de common law deve, necessariamente, partir do estudo do Direito inglês. Ela, entretanto, não passou por renovação do Direito Romano, ou por renovação pela codificação. É um sistema de Direito elaborado na Inglaterra, principalmente pela ação dos Tribunais Reais de Justiça após a invasão normanda liderada por Guilherme, o Conquistador, em 1066.

A continuidade histórica do Direito inglês, sem rupturas marcantes como as ocorridas na família romano-germânica, possui, após a invasão normanda em 1066, três fases: (1) a formação da common law (1066-1485); (2) a rivalidade com a equity (1485-1832) e (3) o período moderno ${ }^{24}$.

Antes da conquista normanda não se pode falar em Direito comum a toda Inglaterra. Os normandos trazem à Inglaterra "um poder forte, centralizado, rico de uma experiência administrativa posta à prova no ducado da Normandia ${ }^{25 \% . ~ A ~ c o m m o n ~ l a w ~ t o r n a r-s e-a ́, ~}$ assim, por oposição aos costumes locais, o Direito comum inglês aplicado pelos Tribunais Reais de Justiça. Estes possuíam uma competência limitada, restringindo-se ao julgamento de grandes questões ${ }^{26}$; entretanto, já no final da idade média são os únicos a administrar a justiça.

Entretanto, os Tribunais Reais tornar-se-ão jurisdições de Direito comum apenas no século XIX, mais especificamente em 1875. Até esta dada, atuariam, teoricamente, como

\footnotetext{
${ }^{21}$ Para um exame pormenorizado da evolução da família romano-germânica ver DAVID, René. Os grandes sistemas de Direito contemporâneo..., p. 33-81.

${ }^{22}$ SOUZA JUNIOR, Cezar Saldanha. A Supremacia do Direito no Estado e seus Modelos Básicos..., p. 94.

${ }^{23}$ Para uma visão completa de todo surgimento e evolução da common law ver, DAVID, René. Os grandes sistemas de Direito contemporâneo..., p. 351-379.

${ }^{24}$ Seguimos a divisão proposta por DAVID, René. Os grandes sistemas de Direito contemporâneo..., p. 356.

${ }^{25}$ DAVID, René. Os grandes sistemas de Direito contemporâneo..., p. 358.

${ }^{26}$ Segundo DAVID, René. Os grandes sistemas de Direito contemporâneo..., p. 360, três grandes questões eram apreciadas pelos Tribunais Reais: (1) finanças reais; (2) propriedade imobiliária e a posse de imóveis e (3) graves questões criminais que se relacionassem com a paz do reino.
} 
jurisdições de exceção. O processo perante os Tribunais Reais de Westminster obedecia a uma maneira de condução da ação muito peculiar, pois à concessão de um writ exigia-se toda uma sequiência de atos, revelando a forte preocupação processual do Direito inglês: Remedies precede rights.

$\mathrm{Na}$ família de common law o processo foi erigido em princípio fundamental para se chegar às soluções justas, devendo os juristas, nas soluções dos casos concretos, não estar adstritos aos statutes, como se faz na realidade romano-germânica, mas sim ao processo, meio pelo qual os juízes atualizam o Direito, pautados na realidade concreta que lhes é apresentada. A aplicação do Direito é realizada caso a caso, ou como diria RADBRUCH, por um processo de muddle through, que poderia ser traduzindo como "improvisação contínua"27.

Mas o princípio da processualidade deve obedecer a determinados requisitos, "a começar, ao menos, pelos de forma, como, por exemplo, o juiz natural, a ampla defesa, a igualdade de armas, a licitude das provas, a presunção de inocência etc..."28. Vê-se, portanto, que não é qualquer processo, mas o princípio do processo jurídico devido.

Assim, o juiz desenvolve o direito nos países de tradição de Common Law. É da essência desse sistema que o direito opere pelo judiciário. Na célebre frase do Juiz Wendell Holmes: "a constituição dos Estados Unidos é o que a Suprema Corte diz que ée", acrescentaríamos, o direito é aquilo que o juiz diz que é, a partir de um caso concreto, operado por um processo jurídico devido.

A expressão judge-made-law tem esta profunda raiz no common law. Assim, o juiz neste sistema, por regra, não é ativista. Ele, em verdade, cumpre o seu papel de improvisação continuada, a cada vez que é chamado a se pronunciar sobre um caso concreto. Não se diga, entretanto, não poder existir ativismo judicial no common law. Ele existe, e quando verificado, é prontamente expelido, respeitando, é claro, às peculiaridades do sistema em que este ativismo se verifica.

\section{A contribuição de McIlWAIN ao Estado de Direito: jurisdictio y gubernaculum}

Ponto de distinção chave, não só para o estudo do constitucionalismo moderno, mas também para entender a racionalidade da common law, foi a contribuição de CHARLES HOWARD McILWAIN ${ }^{30}$, no sentido de distinguir o campo do gubernaculum, do campo da jurisdictio - o campo do governo, do campo do Direito.

McIWAIN analisa no capítulo referente ao constitucionalismo medieval a contribuição do jurista inglês Henry de Bratton (Bracton) para o constitucionalismo moderno, qual seja, demonstrar que no gubernaculum do reino o rei não tem par, e muito menos, superior; na jurisdictio, obrigado por juramento, deve manter a paz, atuando segundo o Direito ${ }^{31}$.

\footnotetext{
${ }^{27}$ RADBRUCH, Gustav. El espíritu del derecho inglês..., p. 25.

${ }^{28}$ SOUZA JUNIOR, Cezar Saldanha. A Supremacia do Direito no Estado e seus Modelos Básicos..., p. 94.

${ }^{29}$ Apud. FERREIRA FILHO. Manoel Gonçalves. Curso de Direito Constitucional. São Paulo: Saraiva, $35^{\mathrm{a}}$ ed., 2009, p. 383.

30 McILWAIN, Charles Howard. Constitucionalismo antiguo y moderno. Madrid: Centro de Estudios constitucionales, 1991, capítulo IV, p. 100 e ss.

${ }^{31}$ Cf. McILWAIN, Charles Howard. Constitucionalismo antiguo y moderno..., com referências expressas às p. 100 e ss.
} 
Duas passagens de McIWAIN demonstram a delimitação dos campos da gubernaculum e do jurisdictio, mas deixemos o próprio falar:

(...) el rey tiene en sus manos el gobierno (gubernaculum) de reino. Lo significativo es que los actos de gobierno estrictamente tales están solo en manos del rey. Ahí él 'no tiene par, mucho menos superior'. Nadie, ni siquiera un juez, puede cuestionar un acto especificamente real poniendo en duda su legitimidad. Se da aquí una separación mucho más profunda entre gubernaculum e jurisdictio que la que establecemos en nuestros tiempo entre gobierno y derecho ${ }^{32}$.

(...) en la jurisdictio, en contraposición al gubernaculum, hay limites a la discrecionalidad del rey establecidos por el derecho positivo y coactivo, de modo que un acto del rey sobrepase dichos limites es ultra vires. (...) Pues en la jurisdicción el rey estaba obligado por su juramento a actuar según derecho y no de otro modo. Aunque los jueces fueran suyos, él los nombrase y actuasen sólo en su nombre, estaban obligados en virtud de propios juramentos a determinar los derechos de los súbditos no según la voluntad del monarca, sino de acuerdo con la ley ${ }^{33}$.

A contribuição do constitucionalismo da Idade Média à separação do gubernaculum da jurisdictio é inequívoca. A delimitação de um campo da política e de um campo do Direito é característica marcante da common law. O juiz, portanto, não entra em questões políticas; a política respeita o espaço jurídico. Ambas, e cada uma, possuem um campo de autonomia delimitado. Esta distinção vai nos ajudar a delimitar o campo de atuação do juiz. Delimitar onde começa o seu ativismo, bem como até onde vão os limites da política.

\section{Estado de direito e de democracia: os problemas do ativismo judicial}

O Estado antes de ser de Direito é de política, de democracia. Neste sentido a melhor expressão para designar o Estado de Direito é Estado Democrático de Direito, e não Estado de Direito Democrático ${ }^{34}$. É a democracia como fundamento (governo do povo), funcionamento (governo pelo povo) e finalidade (e para o povo) que define o direito em nosso sistema jurídico ${ }^{35}$. Assim, o juiz fica adstrito ao cumprimento da lei. Não esquecemos os velhos, mas sábios conselhos de Montesquieu de que o juiz é a bouche de la $\operatorname{loi}^{36}$.

$\mathrm{O}$ ativismo judicial centra-se neste ponto. $\mathrm{O}$ juiz transpassa o campo do direito e ingressa na seara da política. Assim "resolve" problemas políticos por critérios jurídicos. Isto se dá dentre outras razões, pelo desprestígio da lei, ineficiência da política, dificuldade da própria administração, malversação dos recursos públicos...

A realidade brasileira - e não só ela - os países ibero-americanos que misturam Estado, governo e administração, que não separam jurisdição constitucional de jurisdição ordinária, e que não preservam instituições que facilitem o desenvolvimento de maioria

\footnotetext{
${ }^{32}$ McILWAIN, Charles Howard. Constitucionalismo antiguo y moderno..., p. 101-102.

${ }^{33}$ McILWAIN, Charles Howard. Constitucionalismo antiguo y moderno..., p. 109-110.

34 J.J. GOMES CANOTILHO expressa a importância do Estão moderno não se limitar apenas a um Estado de Direito, mas também de democracia. (GOMES CANOTILHO, J. J. Direito Constitucional e Teoria da Constituição. Coimbra: Almedina, $6^{\text {a }}$ ed., 2002, p. 98).

35 Sobre a democracia, por todos, ver: A Crise da Democracia no Brasil. Rio de Janeiro: Forense, 1978. Passim.

${ }^{36}$ MONTESQUIEU. O espírito das leis. Apresentação Renato Janine Ribeiro; tradução Cristina Murachco. $3^{\mathrm{a}}$. ed. São Paulo: Martins Fontes, 2005, Livro XI, passim.
} 
governamental $^{37}$, mesmo querendo, não conseguirão distinguir, com clareza, o que é jurídico do que é político.

Quando se confunde o campo jurídico com o campo político, a consequiência é fatal: o julgador acaba fazendo uma má política, por meios jurídicos. Os exemplos, em nossos tribunais, apresentam-se aos borbotões ${ }^{38}$. Talvez, o mais maléfico deles seja as liminares que concedem internações em hospitais que não possuem vagas. $O$ juiz decide, "juridicamente" um problema de política pública: leitos escassos para pacientes em demasia.

$\mathrm{O}$ atual sistema de controle de constitucionalidade no Brasil também favorece o ativismo judicial. Se na Alemanha, na Espanha, na Itália $^{39}$, ou melhor, no sistema Europeu a competência para declarar a inconstitucionalidade de uma lei é restrita a uma Corte Suprema, a um Tribunal Constitucional; no Brasil, todos os juízes e tribunais são capazes de declarar a inconstitucionalidade de uma lei. O ativismo, assim, na busca de uma solução mágica, na extração de um princípio que fundamente a decisão (razoável ou não), acaba por afrontar à separação de poderes ${ }^{40}$, faz do juiz um verdadeiro legislador e inclusive ex post facto, contrariando o Estado de Direito, em que impera a lei, como decorrência justiça.

\section{Conclusão}

O sistema da separação de poderes, bem como o da separação das funções devem ser repensados em nosso ordenamento jurídico. Cumular no poder judiciário ordinário e no Supremo Tribunal Federal a possibilidade de declarar a inconstitucionalidade das leis favorece o ativismo judicial. Separar e delimitar as funções políticas e as funções jurídicas ajudaria a estabelecer um cenário mais racional de desenvolvimento do Estado de Democracia e de Direito. Assim, a conclusão não pode ser outra: ativismo judicial acaba

\footnotetext{
${ }^{37}$ Ver, SOUZA JUNIOR, Cezar Saldanha. O tribunal constitucional como poder: uma nova teoria da divisão dos poderes. Porto Alegre: Memória editora, 2002; ver ainda, do mesmo autor, Direito Constitucional, Direito Ordinário, Direito Judiciário. Cadernos do Programa de Pós-Graduação em Direito da Universidade Federal do Rio Grande do Sul, março de 2005, p. 7-18.

${ }^{38}$ Colaciono aqui apenas algumas decisões que comprovam o aqui afirmado; me limito, entretanto, a algumas decisões, pois de norte a sul de nosso País, em todos os tribunais elas aparecem como um 'passe de mágica', 'vindo das nuvens' (out of the blue, na expressão inglesa), distribuindo os escassos recursos públicos do orçamento da saúde. Fico pensando no que deve fazer quem não acessa o judiciário, ou quem não conhece uma defensoria pública! Apelação Cível No 70031342652, Oitava Câmara Cível, Tribunal de Justiça do RS, Relator: José Ataídes Siqueira Trindade, Julgado em 31/08/2009; Apelação Cível No 70023603905, Terceira Câmara Cível, Tribunal de Justiça do RS, Relator: Nelson Antônio Monteiro Pacheco, Julgado em 20/08/2009; RE n. 557548/MG, relator o Senhor Ministro CELSO DE MELLO, j. em 08.11.2007, DJ 05.12.2007...

39 Sobre o Controle de Constitucionalidade no Direito Comparado, por todos, ver o hoje clássico: CAPPELLETTI, Mauro. O controle judicial de constitucionalidade das leis no direito comparado. Trad. Aroldo Plínio Gonçalves. Porto Alegre: Sergio Antônio Fabris, 1992.

${ }^{40} \mathrm{O}$ Estado de Direito, pautado na separação dos poderes, implica na redução do ativismo judicial. Sobre este ponto ver o recente trabalho de SILVA RAMOS, Elival da. Parâmetros Dogmáticos do Ativismo Judicial em Matéria Constitucional. São Paulo: Tese apresentada à Faculdade de Direito da Universidade de São Paulo, para inscrição em concurso público visando ao provimento de cargo de professor titular, junto ao Departamento de Direito do Estado, área de Direito Constitucional, 2009, p. 83 e ss.
} 
com o Estado de Democracia, com a roupagem de estar instaurando um verdadeiro Estado de Direito.

\section{Bibliografía}

AQUINO, Tomás de. Suma Teológica. Madrid: Moya y Plaza, 1880, I-I.

BELLO, Pedro Paul. Lo humano: introduccion al personalismo cristiano. Caracas: IFEDEC, 1987.

BOÉCIO. De duabus nat., II, 4.

CAENEGEN, R. C. Van. Judges, Legislators and Professors. Cambridge: University Press, 1996.

CAPPELLETTI, Mauro. O controle judicial de constitucionalidade das leis no direito comparado. Trad. Aroldo Plínio Gonçalves. Porto Alegre: Sergio Antônio Fabris, 1992.

DAVID, René. Os grandes sistemas de Direito contemporâneo. $4^{\mathrm{a}}$ ed. São Paulo: Martins Fontes, 2002.

FERREIRA FILHO, Manoel Gonçalves. Estado de Direito e Constituição. São Paulo: Saraiva, 2007.

. Curso de Direito Constitucional. São Paulo: Saraiva, 35a ed., 2009.

GOMES CANOTILHO, J. J. Direito Constitucional e Teoria da Constituição. Coimbra: Almedina, $6^{\mathrm{a}}$ ed., 2002.

GONELLA, Guido. Bases de uma ordem social. São Paulo: Vozes, 1947.

GROTE, Rainer. Rule of Law, État de Droit and Rechtsstaat. Anais do Congresso da Associação Internacional de Direito Constitucional, Roterdam, 12-16 de Julho de 1999.

McILWAIN, Charles Howard. Constitucionalismo antiguo y moderno. Madrid: Centro de Estudios constitucionales, 1991.

MIRANDA, Jorge. Manual de Direito Constitucional. 3.ed. Coimbra: Coimbra Editora, 1991, Tomo II.

MONTESQUIEU. O espírito das leis. Apresentação Renato Janine Ribeiro; tradução Cristina Murachco. $3^{\text {a }}$. ed. São Paulo: Martins Fontes, 2005.

HEUSCHLING, Luc. État de Droit, Rechtsstaat, Rule of Law. Paris: Dalloz, 2002.

RADBRUCH, Gustav. El espíritu del derecho inglés. Madrid: Marcial Pons, 2001.

SILVA RAMOS, Elival da. Parâmetros Dogmáticos do Ativismo Judicial em Matéria Constitucional. São Paulo: Tese apresentada à Faculdade de Direito da Universidade de São Paulo, para inscrição em concurso público visando ao provimento de cargo de professor titular, junto ao Departamento de Direito do Estado, área de Direito Constitucional, 2009.

SOUZA JUNIOR, Cezar Saldanha. A Supremacia do Direito no Estado Democrático e seus Modelos Básicos. Porto Alegre: [s.ed.], 2002.

. A Crise da Democracia no Brasil. Rio de Janeiro: Forense, 1978.

- (Informação oral). Aulas de Política e Teoria do Estado do Curso de

Direito da Universidade Federal do Rio Grande do Sul, 1. ${ }^{\circ}$ semestre de 2006.

. Direito Constitucional, Direito Ordinário, Direito Judiciário. Cadernos

do Programa de Pós-Graduação em Direito da Universidade Federal do Rio Grande do Sul, março de 2005, pp 7-18. 
. O tribunal constitucional como poder: uma nova teoria da divisão dos poderes. Porto Alegre: Memória editora, 2002.

WALDRON, Jeremy. The Dignity of Legislation. Cambridge: Cambridge University Press, 1999. 